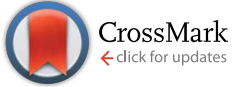

Cite this: Chem. Sci., 2015, 6, 2997

Received 14th December 2014 Accepted 25th February 2015

DOI: $10.1039 / \mathrm{c} 4 \mathrm{sc} 03877 \mathrm{k}$

www.rsc.org/chemicalscience

\section{Total synthesis and biochemical characterization of mirror image barnase $\uparrow$}

\author{
Alexander A. Vinogradov, Ethan D. Evans and Bradley L. Pentelute* \\ In this study we synthesized and characterized mirror image barnase (B. amyloliquefaciens ribonuclease). D- \\ Barnase was identical to L-barnase, when analyzed by liquid chromatography and mass-spectrometry. \\ Proteolysis of the mirror image enzyme revealed that in contrast to its native counterpart, D-barnase was \\ completely stable to digestive proteases. In enzymatic assays, D-barnase had the reciprocal chiral \\ specificity and was fully active towards mirror image substrates. Interestingly, D-barnase also hydrolyzed \\ the substrate of the native chirality, albeit 4000 times less efficiently. This effect was further confirmed \\ by digesting a native 112-mer RNA with the enzyme. Additional studies revealed that barnase \\ accommodates a range of substrates with various chiralities, but the prime requirement for guanosine \\ remains. These studies point toward using mirror image enzymes as modern agents in biotechnology.
}

\section{Introduction}

Mirror image enzymes (MIEs), enantiomers of naturally occurring enzymes, are a promising therapeutically relevant class of biomolecules. These enzymes are thought to be more proteolytically stable and less immunogenic than their native counterparts, while possessing catalytic activity with reciprocal chiral specificity. ${ }^{1}$ Enhanced proteolytic stability and low immunogenicity of mirror image proteins were demonstrated with D-rubredoxin, which was stable to chymotrypsin ${ }^{2}$ and did not elicit an immune response in mice in contrast to its native enantiomer. ${ }^{3}$ The catalytic function of MIEs was studied on the examples of D-HIV-1 protease, which cleaved the D-substrate and not its L-form, ${ }^{4}$ and $\mathrm{D}$-4-oxalocrotonate-tautomerase (4-OT), which acted on the same achiral-substrate as its L-4-OT, but produced the enantiomeric product. ${ }^{5}$ These studies confirmed the reciprocal chiral specificity of MIEs. In a more recent study ${ }^{6}$ the GroEL/ES-assisted folding of mirror image DapA revealed that MIEs may be folded by the native chaperones. Unfortunately, the field of MIEs is still largely unexplored, as only three enzymes were synthesized to date: the mentioned reports represent all published data regarding properties of MIEs.

We undertook this study to systematically investigate properties of an MIE in greater detail. To this end, we synthesized and characterized the enantiomers of $B$. amyloliquefaciens ribonuclease (barnase). Barnase is a potent guanyl-specific, ${ }^{7}$ single strand RNA specific ${ }^{8}$ endonuclease that operates via the classical mechanism of RNA hydrolysis, producing a $2^{\prime}, 3^{\prime}$-cyclic

Department of Chemistry, Massachusetts Institute of Technology, 77 Massachusetts Avenue, Cambridge, MA 02139, USA.E-mail: blp@mit.edu

$\uparrow$ Electronic supplementary information (ESI) available: Materials, methods, and detailed experimental procedures. See DOI: 10.1039/c4sc03877k phosphate as an intermediate. ${ }^{9}$ The enzyme is more active towards long RNA molecules with the optimum $\mathrm{pH}$ at 8.5, but it also hydrolyzes substrates as short as dinucleotides. ${ }^{\mathbf{1 0}} \mathrm{We}$ deemed barnase an ideal target for this study due to its structural simplicity (the protein is comprised of a single 110 amino acid residue polypeptide chain with no cysteines ${ }^{\mathbf{1 1}}$ ), reversible folding-unfolding transition, ${ }^{12}$ and straightforward catalytic activity with a fairly simple readout. Additionally, barnase may be relevant biologically; as bacterial ribonucleases are not inhibited by human ribonuclease inhibitor, barnase exhibits strong cytotoxicity on mammalian cells, and shows promising antitumor activity when conjugated to humanized HER-2 antibody. ${ }^{13}$

\section{Results and discussion}

To synthesize both enantiomers of barnase we used a previously established strategy with minor revisions (Fig. 1a). ${ }^{\mathbf{1 4}}$ In short, four peptide fragments comprising the protein were rapidly assembled on the fast flow peptide synthesis platform ${ }^{\mathbf{1 5}}$ and purified by RP-HPLC. To increase the yields of Liu's oxidation/ native chemical ligation (NCL) protocol $^{16}$ we performed all ligations in two steps, isolating intermediate thioesters by RPHPLC. Thus, the C-terminal hydrazide $\mathrm{H}_{2} \mathrm{~N}-\left[\mathrm{Gly}^{1}-\mathrm{Val}^{13}\right]-\mathrm{CON}_{2} \mathrm{H}_{3}$ was subject to $\mathrm{NaNO}_{2}$ oxidation and 4-mercaptophenylacetic acid (MPAA) transesterification, which afforded the C-terminal thioester of the $\mathrm{N}$-terminal fragment. In the second step the thioester was ligated with $\mathrm{H}_{2} \mathrm{~N}-\left[\mathrm{Cys}^{14}-\mathrm{Val}^{39}\right]-\mathrm{CON}_{2} \mathrm{H}_{3}$ to obtain $\mathrm{H}_{2} \mathrm{~N}-\left[\mathrm{Gly}^{1}-\mathrm{Val}^{39}\right]-\mathrm{CON}_{2} \mathrm{H}_{3}$ with $74 \%$ yield over two steps (the one-pot procedure used in the original synthesis of L-barnase yielded $67 \%$ of the product). In an analogous manner $\mathrm{H}_{2} \mathrm{~N}$ $\left[\mathrm{Cys}^{40}(\mathrm{Acm})-\mathrm{Arg}^{113}\right]-\mathrm{CONH}_{2}$ was synthesized from $\mathrm{H}_{2} \mathrm{~N}$ $\left[\mathrm{Cys}^{40}(\mathrm{Acm})-\mathrm{Glu}^{76}(\mathrm{Cy})\right]-\mathrm{CON}_{2} \mathrm{H}_{3}$ and $\mathrm{H}_{2} \mathrm{~N}-\left[\mathrm{Cys}^{77}-\mathrm{Arg}^{113}\right]-\mathrm{CONH}_{2}$ 


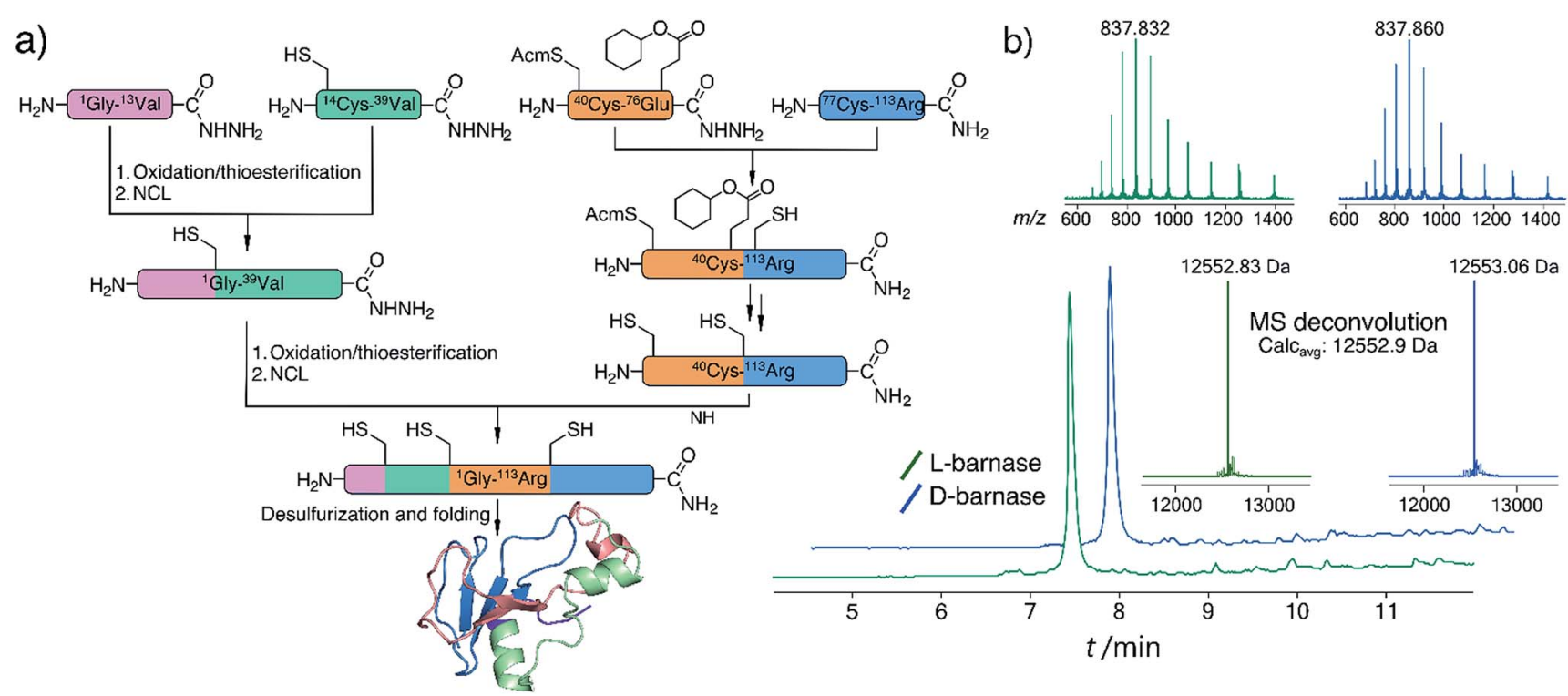

Fig. 1 (a) Synthetic strategy for L- and D-barnase. (b) HPLC-MS (TIC) chromatograms for the synthesized proteins with mass spectra insets for the main peaks. Maximum entropy deconvolution spectra of the MS spectra on the top are displayed on the bottom. For both proteins main identified contaminants were $+32 \mathrm{Da}$ (Ala $\rightarrow$ Cys, incomplete desulfurization), and -57 Da (Gly deletion).

with $85 \%$ yield over two steps, up from $77 \%$ yield obtained originally. After acetamidomethyl and cyclohexyl protecting groups were removed from the C-terminal segment, the final NCL reaction between $\mathrm{H}_{2} \mathrm{~N}-\left[\mathrm{Gly}^{1}-\mathrm{Val}^{39}\right]-\mathrm{CON}_{2} \mathrm{H}_{3}$ and $\mathrm{H}_{2} \mathrm{~N}$ $\left[\mathrm{Cys}^{40}{ }^{-\mathrm{Arg}^{113}}\right]$ - $\mathrm{CONH}_{2}$ afforded full length ${ }^{14,40,77}$ Cys-barnase trimutant. This step proceeded rather slowly and inefficiently during the original synthesis ( $>36$ hours to go to completion with $34 \%$ yield after purification). To accelerate it, we used twofold excess of the N-terminal fragment and increased the concentrations of both peptides, up to $4.5 \mathrm{mM}$ and $9.0 \mathrm{mM}$. These changes increased the yield of the reaction up to $65 \%$ and allowed to run it overnight. Finally, mild desulfurization ${ }^{17}$ with TCEP, MESNa, and VA-044 radical initiator yielded the desired protein, which was refolded from $6 \mathrm{M} \mathrm{Gn} \cdot \mathrm{HCl}$ in $50 \mathrm{mM}$ Tris, $100 \mathrm{mM} \mathrm{NaCl}$ (pH 7.4) buffer. The improved NCL conditions increased the overall yield of the protein to $19 \%$ up from original $12 \%$ (calculated from the purified starting fragments). Both synthesized proteins contained a $\mathrm{Gly}_{3} \mathrm{~N}$-terminal tag to facilitate sortase A-mediated ligation future studies. $\mathrm{L}$ - and D-barnase prepared in this way were characterized by HPLC-MS (Fig. 1b) and found identical to each other by liquid chromatography and mass spectrometry. Additionally, synthetic proteins were similar to recombinant barnase, which lacked the $\mathrm{Gly}_{3}$ tag: the mass difference in the deconvoluted MS spectrum was $171 \mathrm{Da}$, consistent with extra $\mathrm{Gly}_{3}$ for synthetic variants (ESI 3.1†).

With both $\mathrm{L}^{-}$and $\mathrm{D}$-barnase proteins in hand we turned to characterizing the catalytic activity of these enzymes. As the RNase activity assay we utilized a modified version of the fast, supersensitive fluorogenic assay developed by Raines and colleagues. ${ }^{18}$ The substrates for the assay are DNA/RNA hybrids with a single cleavage site, which provides for a homogeneous substrate needed to establish kinetic parameters for enzyme catalyzed hydrolysis (Fig. 2a). During the cleavage of the substrate, fluorescence resonance energy transfer between 6carboxyfluorescein (6-FAM) and 6-carboxytetramethyl-rhodamine (6-TAMRA) fluorophores, installed on the $5^{\prime}$ and $3^{\prime}$ respectively, is perturbed. Thus, the increase in fluorescence of 6-FAM at $515 \mathrm{~nm}$ upon excitation at $495 \mathrm{~nm}$ can be monitored as a function of time to measure kinetics of the substrate hydrolysis. Enzyme kinetic parameters (primarily, $k_{\text {cat }} / K_{\mathrm{M}}$ ) can then be obtained by the non-linear regression of experimental data to the enzyme catalyzed first-order rate equation (ESI $2.2 \dagger$ ). In this study we investigated several different tetraoligonucleotide substrates of the common structure 6-FAM- $\mathrm{dA}^{\mathrm{X}}-\mathrm{rN}^{\mathrm{X}}$ $d A^{\mathrm{x}}-\mathrm{dA} \mathrm{A}^{\mathrm{x}}$-6-TAMRA, henceforth $\mathrm{A}^{\mathrm{x}} \mathrm{N}^{\mathrm{x}} \mathrm{A}^{\mathrm{x}} \mathrm{A}^{\mathrm{x}}$, where $\mathrm{N}$ is a certain nucleotide, and the superscript $\mathrm{X}$ annotates the chirality of the sugar (D-sugars constitute native RNA and L-sugars-its enantiomer). In a typical assay, enzyme (100 pM to $100 \mathrm{nM}$ ) was added to 50-200 nM substrate in MES buffer (100 mM MES, 100 $\mathrm{mM} \mathrm{NaCl}, \mathrm{pH}$ 6.0), and the fluorescence emission was monitored. In cases where enzyme was unable to hydrolyze the substrate completely in under 60 minutes, an additional aliquot of enzyme was added to promote hydrolysis and measure the final fluorescence of the fully hydrolyzed material.

We first compared the catalytic efficiency of synthetic L-barnase to its recombinant analogue. Because barnase is known as a guanyl-specific endonuclease, we studied the hydrolysis of $\mathrm{A}^{\mathrm{D}} \mathrm{G}^{\mathrm{D}} \mathrm{A}^{\mathrm{D}} \mathrm{A}^{\mathrm{D}}$. We found that synthetic $\mathrm{L}$-barnase had a $k_{\text {cat }} / K_{\mathrm{M}}$ value of $(1.2 \pm 0.1) \times 10^{7} \mathrm{M}^{-1} \mathrm{~s}^{-1}$ (Table 1), in line with the activity of the recombinant enzyme $\left((1.3 \pm 0.4) \times 10^{7} \mathrm{M}^{-1} \mathrm{~s}^{-1}\right.$, Fig. 2b). For D-barnase, we expected the reciprocal catalytic activity (i.e., hydrolysis of the mirror image substrate $\mathrm{A}^{\mathrm{L}} \mathrm{G}^{\mathrm{L}} \mathrm{A}^{\mathrm{L}} \mathrm{A}^{\mathrm{L}}$ ). Indeed, D-barnase hydrolyzed this substrate efficiently with $k_{\text {cat }} /$ $K_{\mathrm{M}}=(1.1 \pm 0.2) \times 10^{7} \mathrm{M}^{-1} \mathrm{~s}^{-1}$, thus confirming our hypothesis. These data allowed us to conclude that both synthetic enzymes had full catalytic activity. 
a)

b)
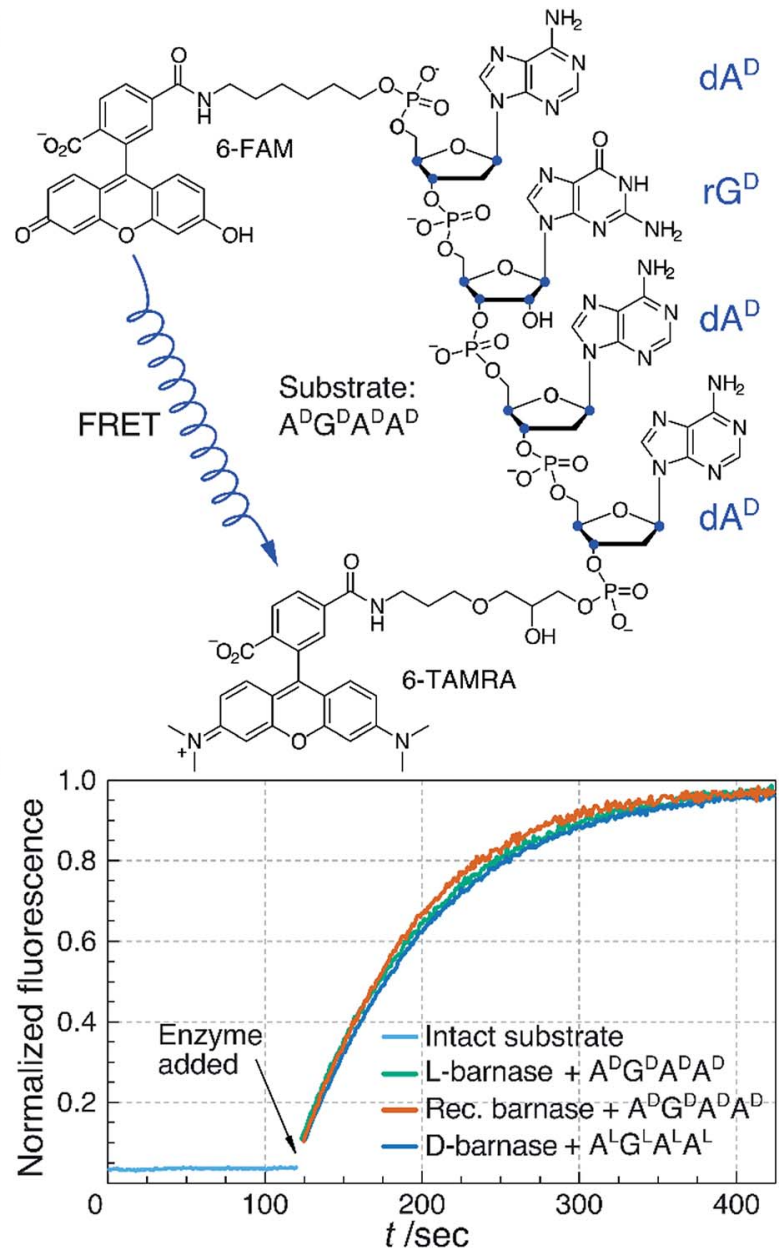

Fig. 2 (a) Chemical structure of the $A^{D} G^{D} A^{D} A^{D}$ fluorogenic substrate. Stereogenic centers are highlighted in blue. (b) Biochemical characterization of synthetic L- and D-barnase using the fluorogenic assay. One representative kinetic curve is shown for each enzyme. Barnase concentration was $1.0 \mathrm{nM}$ in all cases.

Next, we sought to study the substrate stereospecificity of the enzymes, i.e., to evaluate the hydrolysis of $\mathrm{A}^{\mathrm{L}} \mathrm{G}^{\mathrm{L}} \mathrm{A}^{\mathrm{L}} \mathrm{A}^{\mathrm{L}}$ by L-barnase and of $\mathrm{A}^{\mathrm{D}} \mathrm{G}^{\mathrm{D}} \mathrm{A}^{\mathrm{D}} \mathrm{A}^{\mathrm{D}}$ by D-barnase. Unexpectedly, we found significant remaining activity in both cases: the $k_{\text {cat }} / K_{\mathrm{M}}$ for $\mathrm{L}^{-}$ barnase was $(3.2 \pm 0.2) \times 10^{3} \mathrm{M}^{-1} \mathrm{~s}^{-1}$, and $(3.0 \pm 0.6) \times 10^{3}$ $\mathrm{M}^{-1} \mathrm{~s}^{-1}$ for D-barnase. Although these values are $\sim 4000$ times lower than the corresponding ones for the native substrates, $k_{\text {cat }} / K_{\mathrm{M}}$ of $3 \times 10^{3} \mathrm{M}^{-1} \mathrm{~s}^{-1}$ still represents a fairly potent enzyme ${ }^{19}$ with the rate acceleration of $\sim 10^{10}$ over the uncatalyzed RNA hydrolysis. ${ }^{20}$ The similarity of $k_{\text {cat }} / K_{\mathrm{M}}$ values suggest the observation is not due to an artifact or RNase contamination. However, we performed additional experiments to exclude these possibilities. We used barstar, a well-known barnasespecific inhibitor, ${ }^{21}$ to probe its efficiency in the assays. We found that addition of two equivalents of barstar completely abolished the catalytic activity of $\mathrm{L}$-barnase for both $\mathrm{A}^{\mathrm{D}} \mathrm{G}^{\mathrm{D}} \mathrm{A}^{\mathrm{D}} \mathrm{A}^{\mathrm{D}}$ and $\mathrm{A}^{\mathrm{L}} \mathrm{G}^{\mathrm{L}} \mathrm{A}^{\mathrm{L}} \mathrm{A}^{\mathrm{L}}$, confirming that $\mathrm{L}$-barnase is responsible for the cleavage of the substrates. Additionally, recombinant L-barnase, obtained independently from synthetic enzymes, had $k_{\text {cat }} / K_{\mathrm{M}}$ of $(3.3 \pm 0.3) \times 10^{3} \mathrm{M}^{-1} \mathrm{~s}^{-1}$ towards $\mathrm{A}^{\mathrm{L}} \mathrm{G}^{\mathrm{L}} \mathrm{A}^{\mathrm{L}} \mathrm{A}^{\mathrm{L}}$. Finally, a common source of RNase contamination are RNase A family enzymes, which are pyrimidine rather than purine specific, ${ }^{22}$ and thus are not expected to cleave the studied substrates. Accordingly, we did not detect hydrolysis of either $\mathrm{A}^{\mathrm{D}} \mathrm{G}^{\mathrm{D}} \mathrm{A}^{\mathrm{D}} \mathrm{A}^{\mathrm{D}}$ or $\mathrm{A}^{\mathrm{L}} \mathrm{G}^{\mathrm{L}} \mathrm{A}^{\mathrm{L}} \mathrm{A}^{\mathrm{L}}$ substrates by RNase A of up to $50 \mathrm{nM}$. Taken together, these data suggested that barnase may accommodate substrates of the opposite chirality.

To further investigate this phenomenon, we studied the hydrolysis of "mixed chirality" substrates, $\mathrm{A}^{\mathrm{L}} \mathrm{G}^{\mathrm{D}} \mathrm{A}^{\mathrm{L}} \mathrm{A}^{\mathrm{L}}$ and its enantiomer $\mathrm{A}^{\mathrm{D}} \mathrm{G}^{\mathrm{L}} \mathrm{A}^{\mathrm{D}} \mathrm{A}^{\mathrm{D}}$, by L- and $\mathrm{D}$-barnase. We found that both substrates were hydrolyzed by the enzymes less efficiently than the native substrates, but significantly faster than tetranucleotides with the fully inverted stereochemistry (Table 1). Thus, Dbarnase hydrolyzed $\mathrm{A}^{\mathrm{D}} \mathrm{G}^{\mathrm{L}} \mathrm{A}^{\mathrm{D}} \mathrm{A}^{\mathrm{D}}$, (the recognition guanosine had the correct chirality, while the rest was inverted) only $\sim 100$ times less efficiently than $\mathrm{A}^{\mathrm{L}} \mathrm{G}^{\mathrm{L}} \mathrm{A}^{\mathrm{L}} \mathrm{A}^{\mathrm{L}}$ with $k_{\text {cat }} / K_{\mathrm{M}}$ as high as $(1.0$ $\pm 0.5) \times 10^{5} \mathrm{M}^{-1} \mathrm{~s}^{-1}$. The second substrate, $\mathrm{A}^{\mathrm{D}} \mathrm{G}^{\mathrm{L}} \mathrm{A}^{\mathrm{D}} \mathrm{A}^{\mathrm{D}}$, which had only the guanosine chirality inverted, was hydrolyzed by $\mathrm{D}^{-}$ barnase $\sim 350$ times slower than its native substrate. These results were corroborated by the data for $\mathrm{L}$-barnase. At the same time, we could not detect hydrolysis of either $\mathrm{A}^{\mathrm{D}} \mathrm{C}^{\mathrm{D}} \mathrm{A}^{\mathrm{D}} \mathrm{A}^{\mathrm{D}}$ or its enantiomer, $\mathrm{A}^{\mathrm{L}} \mathrm{C}^{\mathrm{L}} \mathrm{A}^{\mathrm{L}} \mathrm{A}^{\mathrm{L}}$, by $\mathrm{L}$ - or $\mathrm{D}$-barnase. As a positive control for this experiment, we demonstrated the efficient hydrolysis of $\mathrm{A}^{\mathrm{D}} \mathrm{C}^{\mathrm{D}} \mathrm{A}^{\mathrm{D}} \mathrm{A}^{\mathrm{D}}$ by RNase $\mathrm{A}$, which was consistent with previous reports. Interestingly, we could not detect the cleavage of $\mathrm{A}^{\mathrm{L}} \mathrm{C}^{\mathrm{L}} \mathrm{A}^{\mathrm{L}} \mathrm{A}^{\mathrm{L}}$ by RNase $\mathrm{A}$.

Collectively, these results confirmed that barnase allows variations in the chirality of its substrates. The chirality of the main recognition nucleoside, guanosine, appears to be more

Table 1 Catalytic activities of select RNases towards different fluorogenic substrates. $k_{\text {cat }} / K_{M}$ values in $\mathrm{M}^{-1} \mathrm{~s}^{-1} \pm$ one standard deviation are displayed

\begin{tabular}{lllll}
\hline & Recombinant barnase & L-Barnase & D-Barnase & RNase A \\
\hline $\mathrm{A}^{\mathrm{D}} \mathrm{G}^{\mathrm{D}} \mathrm{A}^{\mathrm{D}} \mathrm{A}^{\mathrm{D}}$ & $(1.3 \pm 0.4) \times 10^{7}$ & $(1.2 \pm 0.1) \times 10^{7}$ & $(3.0 \pm 0.6) \times 10^{3}$ & $-{ }^{a}$ \\
$\mathrm{~A}^{\mathrm{L}} \mathrm{G}^{\mathrm{L}} \mathrm{A}^{\mathrm{L}}$ & $(3.3 \pm 0.3) \times 10^{3}$ & $(3.2 \pm 0.2) \times 10^{3}$ & $(1.1 \pm 0.2) \times 10^{7}$ & $-{ }^{a}$ \\
$\mathrm{~A}^{\mathrm{D}} \mathrm{G}^{\mathrm{L}} \mathrm{A}^{\mathrm{D}} \mathrm{A}^{\mathrm{D}}$ & n.d. & $(6.9 \pm 0.8) \times 10^{4}$ & $(1.0 \pm 0.5) \times 10^{5}$ & n.d. $^{b}$ \\
$\mathrm{~A}^{\mathrm{L}} \mathrm{G}^{\mathrm{D}} \mathrm{A}^{\mathrm{L}} \mathrm{A}^{\mathrm{L}}$ & n.d. $^{b}$ & $(1.7 \pm 0.1) \times 10^{5}$ & $(3.0 \pm 0.7) \times 10^{4}$ & n.d. $^{b}$ \\
$\mathrm{~A}^{\mathrm{D}} \mathrm{C}^{\mathrm{D}} \mathrm{A}^{\mathrm{D}} \mathrm{A}^{\mathrm{D}}$ & n.d. $^{b}$ & $-^{a}$ & $-^{a}$ & $(4.9 \pm 0.3) \times 10^{7}$ \\
$\mathrm{~A}^{\mathrm{L}} \mathrm{C}^{\mathrm{L}} \mathrm{A}^{\mathrm{L}} \mathrm{A}^{\mathrm{L}}$ & n.d. & $-{ }^{b}$ & $-^{a}$ &
\end{tabular}

${ }^{a}$ Hydrolysis was not detected $\left(k_{\mathrm{cat}} / K_{\mathrm{M}}<1 \mathrm{M}^{-1} \mathrm{~s}^{-1}\right.$, upper bound estimation). ${ }^{b}$ Not determined. 
important than the chirality of the rest of the substrate. Moreover, it seems barnase is not simply promiscuous because it did not hydrolyze ACAA substrates, where the key guanosine was replaced by a pyrimidine-based nucleoside. Interestingly, we also found that RNase A did not hydrolyze an enantiomer of its native substrate, which implies that the low substrate stereospecificity is not a universal phenomenon amongst digestive ribonucleases.

To expand our findings beyond the fluorogenic assay we sought to study the hydrolysis of native RNA by D-barnase. Towards this end, we incubated a $70 \mu \mathrm{g} \mathrm{mL} \mathrm{m}^{-1}$ solution of a native 112-mer RNA in $10 \mathrm{mM}$ Tris, $50 \mathrm{mM} \mathrm{NaCl}$ buffer (pH 7.4) with various concentrations of D-barnase or $450 \mathrm{nM}$ L-barnase for up to 4 hours and analyzed the RNA digest products by performing $10 \%$ denaturing PAGE (ESI $3.1 \dagger$ ). As demonstrated in Fig. 3, the presence of the low molecular weight bands in cases where $\mathrm{D}$-barnase was added, but not in the negative control lane, indicates that D-barnase cleaved native RNA, albeit slower than L-barnase. The latter observation is evident from digests by $450 \mathrm{nM}$ D-barnase versus L-barnase. As such, we confirmed that the results of the fluorogenic assay translate into more complex systems, involving native substrates, and thus, that D-barnase is active towards D-RNA.

In another part of the study we compared the stability of $\mathrm{L}_{-}$- and D-barnase towards common digestive proteases in vitro. Proteolysis of mirror image proteins was investigated before with metalbound D-rubredoxin, which was completely stable to chymotrypsin in contrast to its enantiomer. ${ }^{2}$ Although there is evidence for the enhanced proteolytic stability of short, mostly unfolded Dpeptides, ${ }^{23,24}$ the rubredoxin study remains the only published example of such behavior for folded mirror image proteins. We aimed to study the proteolytic stability of an MIE in greater detail, assaying different proteases and digestion conditions.

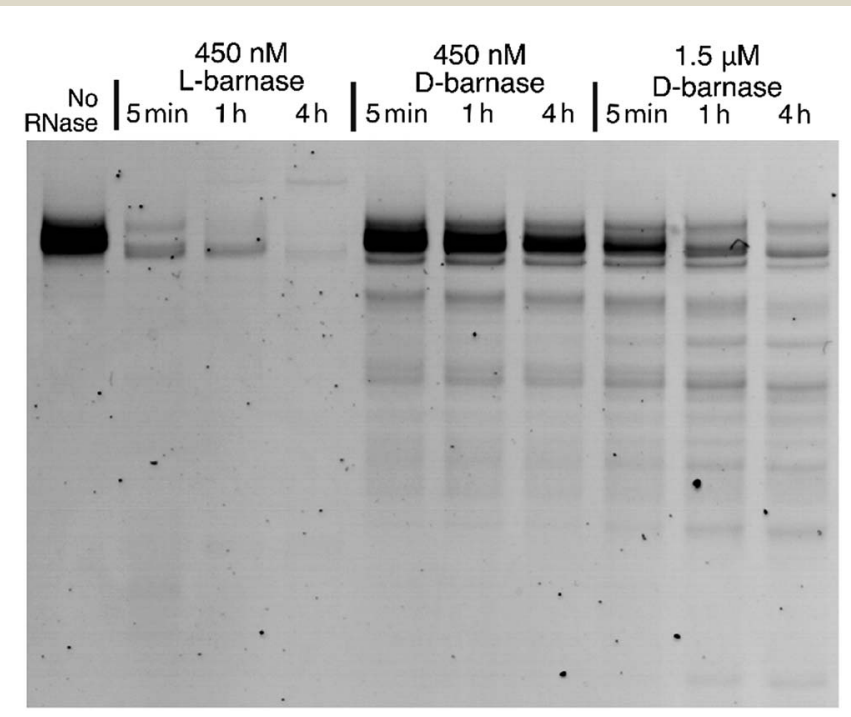

Fig. 3 The RNA gel showing the digest of 112 nucleotide-long D-RNA by $450 \mathrm{nM}$ L-barnase, $450 \mathrm{nM}$ D-barnase, and $1.5 \mu \mathrm{M}$ D-barnase over the course of four hours. The negative control (no RNase added) is shown on the left. The image is digitally modified by inverting the color scheme and adjusting the contrast.
As proteases for this study we selected bovine trypsin, $\alpha$ chymotrypsin, proteinase $\mathrm{K}$, porcine elastase type IV, papain, and $S$. griseus protease (actinase E). These enzymes were chosen for their robust digestive proteolytic activities and a wide range of substrate specificities. Papain represented cysteine superfamily proteases, while other enzymes were serine proteases. Additionally, we wanted to assay enzymes, which are able to recognize and cleave peptide bonds after glycine. Since glycine is achiral, we hypothesized that such proteases may potentially recognize and accommodate glycine residues in mirror image proteins, allowing for the hydrolysis of these substrates. Although glycine-specific digestive proteases are uncommon, both elastase and papain are reported to cleave their substrates after glycine fairly efficiently. ${ }^{25,26}$

First, we performed the non-denaturing, in-solution digestion of $\mathrm{L}^{-}$and $\mathrm{D}^{-}$barnase by the selected proteases. Proteins were incubated in appropriate buffers (ESI $3.2 \dagger$ ) at $37^{\circ} \mathrm{C}$ for up to 19 hours with a $15: 1$ ratio of barnase to protease. The extent of the digestion was determined by HPLC-MS analysis (ESI 3.2.1†), and by measuring the remaining ribonucleatic activity via the fluorogenic assay. As shown in Table 2 and Fig. 4, we found that after 19 hours of digestion L-barnase demonstrated differential stability towards proteases: trypsin-digested barnase had 36\% its native activity, while in the case of proteinase $\mathrm{K}$ less than $0.2 \%$ activity remained. In all six cases L-barnase lost a significant portion of its catalytic activity. In contrast, D-barnase proved completely stable to all assayed proteases; it retained full catalytic activity, and no digestion products could be detected by HPLC-MS.

Additionally, we performed a more forcing in-solution denaturing digestion of $\mathrm{L}^{-}$and $\mathrm{D}$-barnase using the most potent protease, proteinase $\mathrm{K}$. To denature the protein, barnase was incubated in $6 \mathrm{M} \mathrm{Gn} \cdot \mathrm{HCl}, 50 \mathrm{mM}$ Tris buffer $(\mathrm{pH} \mathrm{7.4})$ at $95^{\circ} \mathrm{C}$ for 20 minutes, and then digested with proteinase $\mathrm{K}$ (barnase : protease $=2: 1$ ) in $2 \mathrm{M} \mathrm{Gn} \cdot \mathrm{HCl}$ at $37^{\circ} \mathrm{C}$. We found that D-barnase was completely stable to proteolysis even under such forcing conditions, in stark contrast to L-barnase, which was digested completely (ESI 3.2.2†). Finally, we attempted to digest D-barnase with proteinase $\mathrm{K}$ by increasing the digestion time. Using HPLCMS analysis we did not detect any digestion products after 168

Table 2 Remaining RNase catalytic activity of L- and D-barnase after the proteolytic digestion with select proteases. Values for the remaining barnase activity are normalized to the negative control experiment, where no protease was added to the enzyme, and are displayed as the percentage of the full ribonuclease activity \pm one standard deviation

\begin{tabular}{lrr}
\hline Protease & L-Barnase & D-Barnase \\
\hline No protease & $100.0 \pm 6.4$ & $100.0 \pm 5.1$ \\
Trypsin & $36.7 \pm 2.0$ & $108.0 \pm 8.9$ \\
Chymotrypsin & $9.2 \pm 0.5$ & $103.1 \pm 5.3$ \\
Proteinase K & $0.2 \pm<0.1$ & $99.8 \pm 8.1$ \\
Elastase & $0.6 \pm<0.1$ & $103.5 \pm 3.3$ \\
Papain & $0.8 \pm<0.1$ & $96.6 \pm 4.3$ \\
Actinase E & $0.3 \pm<0.1$ & $101.4 \pm 7.3$
\end{tabular}



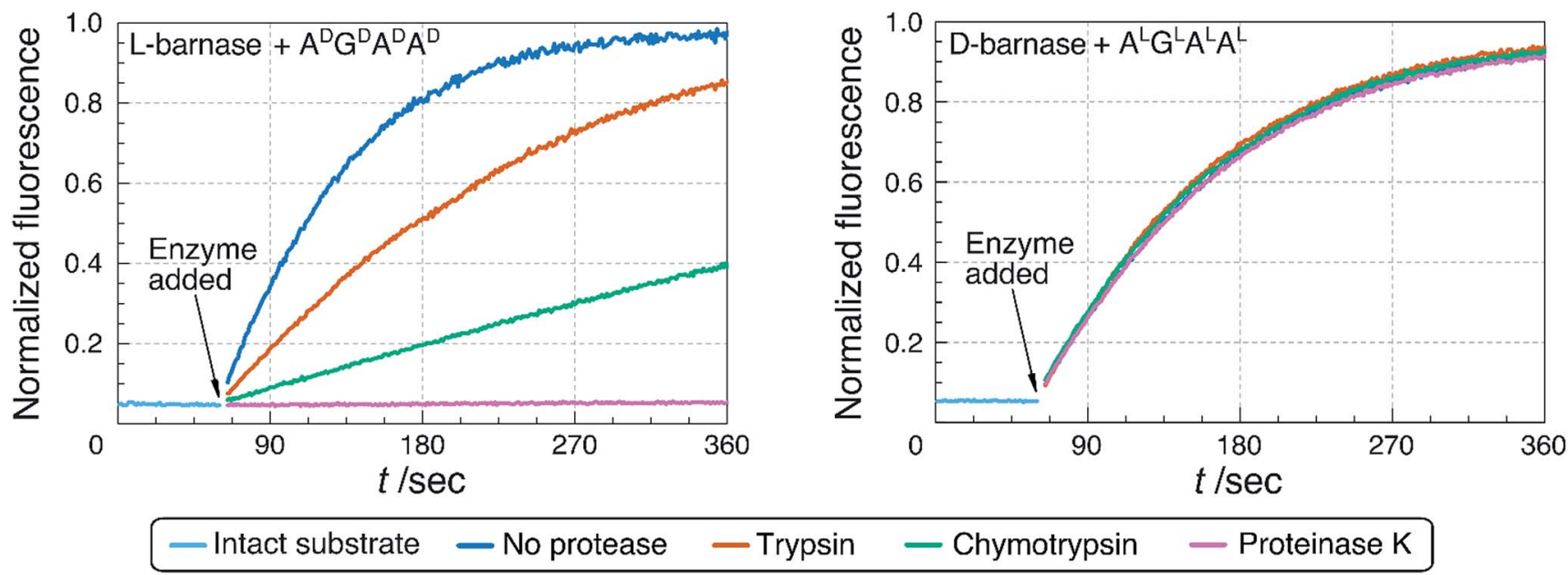

Fig. 4 Comparison of the proteolytic stability of L- and D-barnase. Remaining catalytic activity of the enzymes, associated with the extent of the proteolytic digestion, was measured using the fluorogenic assay. Three out of six assayed proteases are not displayed for clarity. Digestion of 1.0 $\mathrm{nM}$ L-barnase with different proteases was assayed using $A^{D} G^{D} A^{D} A^{D}$ as a substrate (data shown on the left). Digestion of $0.8 \mathrm{nM} D-$ barnase with different proteases was assayed using $A^{L} G^{L} A^{L} A^{L}$ as a substrate (on the right).

hours (1 week) of incubating D-barnase with proteinase K. The digest was indistinguishable from a negative control experiment, where no protease was added to the enzyme (ESI 3.2.3†).

\section{Conclusions}

In summary, we successfully synthesized and characterized mirror image barnase. We found that the enzyme was fully active towards mirror image RNA model substrates and was somewhat promiscuous to its substrate chirality. After the systematic investigation of this phenomenon we used mirror image barnase to demonstrate the cleavage of the native RNA by a mirror image enzyme. Separately, we found that D-barnase appears to be extremely proteolytically stable. Our experiments revealed that neither cysteine nor serine superfamily proteases are able to cleave it even under forcing conditions. Contrary to our initial hypothesis D-barnase was completely stable towards proteases that are able to cleave peptide bonds after achiral glycine. In short, we were unable to find proteases and/or reaction conditions which would lead to the digestion of $\mathrm{D}^{-}$ barnase.

The results of this study pose a number of questions. First, it is unclear how barnase recognizes and cleaves substrates of the opposite chirality. The enzyme is known to have several subsites, which facilitate the substrate binding and its proper orientation for catalysis..$^{10}$ Our data are consistent with this model, as we observed a range of $k_{\text {cat }} / K_{\mathrm{M}}$ values by only changing the chirality of AGAA tetranucleotide. It is conceivable that substrates of the mixed chirality, e.g. $\mathrm{A}^{\mathrm{L}} \mathrm{G}^{\mathrm{D}} \mathrm{A}^{\mathrm{L}} \mathrm{A}^{\mathrm{L}}$, occupy only certain subsites in the enzyme, e.g. the guanosine binding subsite in this case, and thus the catalysis may still proceed. It is also unclear whether this enzymatic activity is merely spontaneous or was subject to the evolutionary selection at some point. At this time we are unaware of any practical implications of such catalysis: to the best of our knowledge, RNA of Lconfiguration is unknown in nature.
Nevertheless, our study suggests that at least in some cases enzymes may utilize substrates of the opposite chirality. The mirror image form of such an enzyme will then act on the same targets as its native counterpart. Although decreased catalytic efficiency is expected, the enzyme may still achieve a notable rate acceleration. This property of MIEs can be highly desirable from the biotechnology standpoint for, as we confirmed in the case of barnase, MIEs can be extraordinarily resistant to proteolysis and at the same time carry the native biological function. Importantly, this effect may manifest itself without protein engineering and/or evolution of the enzyme. As we also found with the example of RNase A, this effect by no means is universal, and more investigations would be needed to establish the generality of our findings.

\section{Acknowledgements}

We are indebted to Prof. J. Stubbe, Prof. M. Shoulders, and M. Simon for critical discussions and helpful suggestions throughout the course of the work. We thank Prof. E. Nolan for providing some laboratory equipment used to carry out the study, as well as T. Nakashige and H. Chileveru for expert technical assistance and A. Rabideau for help with protein expression. This research was supported by Amgen summer graduate fellowship for A.V. and funded by MIT start-up funds, MIT Reed Fund, Desphande Center Innovation Award, and DARPA (Award \#023504-001) for B.L.P. Any opinions, findings, and conclusions or recommendations expressed in this publication are those of the author(s) and do not necessarily reflect the views of DARPA.

\section{Notes and references}

1 S. Kent, Y. Sohma, S. Liu, D. Bang, B. Pentelute and K. Mandal, J. Pept. Sci., 2012, 18, 428-436.

2 L. Zawadzke and J. Berg, J. Am. Chem. Soc., 1992, 114, 40024003. 
3 H. Dintzis, D. Symer, R. Dintzis, L. Zawadzke and J. Berg, Proteins: Struct., Funct., Genet., 1993, 16, 306-308.

4 R. Milton, S. Milton and S. Kent, Science., 1990, 256, 14451448.

5 M. Fitzgerald, I. Chernushevich, K. Standing, S. Kent and C. Whitman, J. Am. Chem. Soc., 1995, 117, 11075-11080.

6 M. Weinstock, M. Jacobsen and M. Kay, Proc. Natl. Acad. Sci. U. S. A., 2014, 111, 11679-11684.

7 G. Rushizky, A. Greco, R. Hartley and H. Sober, Biochemistry, 1963, 2, 787-793.

8 A. Buckle and A. Fersht, Biochemistry, 1994, 33, 1644-1653.

9 D. Mossakowska, K. Nyberg and A. Fersht, Biochemistry, 1989, 28, 3843-3850.

10 A. Day, D. Parsonage, S. Ebel, T. Brown and A. Fersht, Biochemistry, 1992, 31, 6390-6395.

11 E. Barker and R. Hartley, Nature, 1972, 235, 15-16.

12 C. Johnson and A. Fersht, Biochemistry, 1995, 34, 6795-6804.

13 E. Edelweiss, T. Balandin, J. Ivanova, G. Lutsenko, O. Leonova, V. Popenko, A. Sapozhnikov and S. Deyev, PLoS One, 2008, 3, e2434.

14 S. Mong, A. Vinogradov, M. Simon and B. Pentelute, ChemBioChem, 2014, 15, 721-733.
15 M. Simon, P. Heider, A. Adamo, A. Vinogradov, S. Mong, X. Li, T. Berger, R. Policarpo, C. Zhang, Y. Zou, X. Liao, A. Spokoyny, K. Jensen and B. Pentelute, ChemBioChem, 2014, 15, 713-720.

16 G. Fang, Y. Li, F. Shen, Y. Huang, J. Li, Y. Lin, H. Cui and L. Liu, Angew. Chem., Int. Ed., 2011, 50, 7645-7649.

17 Q. Wan and S. Danishefsky, Angew. Chem., Int. Ed., 2007, 46, 9248-9252.

18 B. Kelemen, T. Klink, M. Behlke, S. Eubanks, P. Leland and R. Raines, Nucleic Acids Res., 1999, 27, 3696-3701.

19 A. Bar-Even, E. Noor, Y. Savir, W. Liebermeister, D. Davidi, D. Tawfik and R. Milo, Biochemistry, 2011, 50, 4402-4410.

20 Y. Li and R. Breaker, J. Am. Chem. Soc., 1999, 121, 5364-5372. 21 R. Hartley, Trends Biochem. Sci., 1989, 14, 450-454.

22 C. Cuchillo, M. Nogués and R. Raines, Biochemistry, 2011, 50, 7835-7841.

23 S. Miller, R. Simon, S. Ng, R. Zuckermann, J. Kerr and W. Moos, Drug Dev. Res., 1995, 35, 20-32.

24 R. Tugyi, K. Uray, D. Iván, E. Fellinger, A. Perkins and F. Hudecz, Proc. Natl. Acad. Sci. U. S. A., 2005, 102, 413-418. 25 S. Narayanan and R. Anwar, Biochem. J., 1969, 114, 11-17. 26 J. de Jersey, Biochemistry, 1970, 9, 1761-1767. 